\title{
Long-term Effects of Mitiglinide in Japanese Diabetics Inadequately Controlled with DPP-4 Inhibitor or Biguanide Monotherapy
}

\author{
Kohei Kaku • Nobuya Inagaki $\cdot$ Naoki Kobayashi
}

To view enhanced content go to www.diabetestherapy-open.com

Received: October 11, 2013 / Published online: February 1, 2014

(c) The Author(s) 2014. This article is published with open access at Springerlink.com

\section{ABSTRACT}

Introduction: The goal of treatment in diabetes is to control hyperglycemia to near-normal glucose levels, which is important to prevent the progression of microvascular and macrovascular complications. Mitiglinide is a rapid- and short-acting insulinotropic sulfonylurea receptor ligand that is known to improve postprandial hyperglycemia in patients with type 2 diabetes. The aim of this study was to investigate the long-term efficacy and safety of mitiglinide in Japanese type 2 diabetic

ClinicalTrials.gov identifier: NCT01333592.

Electronic supplementary material The online version of this article (doi:10.1007/s13300-014-0051-5) contains supplementary material, which is available to authorized users.

\section{K. Kaku (ه)}

Division of Diabetes, Endocrinology

and Metabolism, Kawasaki Medical School,

Okayama, Japan

e-mail: kka@med.kawasaki-m.ac.jp

N. Inagaki

Department of Diabetes, Endocrinology

and Nutrition, Graduate School of Medicine,

Kyoto University, Kyoto, Japan

N. Kobayashi

Division of Clinical Development, Kissei

Pharmaceutical Co. Ltd, Matsumoto, Japan patients inadequately controlled by dipeptidyl peptidase-4 (DPP-4) inhibitor or biguanide monotherapy.

Methods: In patients with type 2 diabetes mellitus (T2DM) receiving a stable monotherapy regimen with a DPP-4 inhibitor or biguanide added to dietary therapy, an additional $10 \mathrm{mg}$ mitiglinide was administered for 52 weeks. The efficacy end points were postprandial plasma glucose (PPG) (30 min, $1 \mathrm{~h}, 2 \mathrm{~h})$, postprandial insulin $(30 \mathrm{~min}, 1 \mathrm{~h}$, $2 \mathrm{~h}$ ), insulinogenic index, 1,5-anhydroglucitol (1,5-AG), glycated hemoglobin (HbA1c), and fasting plasma glucose. The safety end points included the incidence and types of adverse events and adverse drug reactions.

Results: A total of 136 patients with T2DM were eligible for enrollment in this study and received mitiglinide. The average HbA1c before the start of mitiglinide administration (baseline) was $7.47 \%$ in the DPP-4 inhibitor combined treatment group (DPP-4 inhibitor CTG) and $7.50 \%$ in the biguanide combined treatment group (biguanide CTG), and the $2 \mathrm{~h}$ PPG was 248.1 and $243.3 \mathrm{mg} / \mathrm{dL}$, respectively. Following the addition of mitiglinide to the treatment regimen for 52 weeks, the early 
postprandial decrease in insulin secretion improved and PPG improved in both the DPP4 inhibitor CTG and biguanide CTG. At final evaluation, the $\mathrm{HbA} 1 \mathrm{c}<7.0 \%$ achievement rate was $57.4 \%$ in the DPP-4 inhibitor CTG and $29.2 \%$ in the biguanide CTG. The incidence of hypoglycemia in the DPP-4 inhibitor CTG and biguanide CTG was 3.0\% (2/67 patients) and $2.9 \% \quad(2 / 69$ patients), respectively. The hypoglycemic symptoms were mild in all cases. Conclusion: Combination therapy with mitiglinide and DPP-4 inhibitors or biguanides improved glycemic control over the long term without increasing risks to safety due to events such as hypoglycemia, and this is a clinically promising therapeutic strategy in T2DM.

Keywords: Biguanide; Combination therapy; DPP-4 inhibitor; HbA1c; Mitiglinide; Postprandial; Type 2 diabetes

\section{INTRODUCTION}

Diabetes mellitus is characterized by chronic hyperglycemia and other metabolic abnormalities due to insufficient action of insulin. Diabetes is classified as type 1 diabetes mellitus (T1DM) or type 2 diabetes mellitus (T2DM) based on its etiology. The pathogenesis of T2DM involves a combination of impaired insulin secretion from pancreatic $\beta$ cells and insulin resistance. Hyperglycemia develops from this insulin-insufficient state, often presenting early as postprandial hyperglycemia.

The goal of treatment in diabetes is to control hyperglycemia to near-normal glucose levels. This is important to prevent progression to microvascular complications, as well as to macrovascular complications such as myocardial infarction. Postprandial hyperglycemia has recently been reported to be an independent risk factor for arteriosclerotic disease [1]. The Diabetes Epidemiology: Collaborative analysis of Diagnostic criteria in Europe (DECODE) study reported a positive correlation between $2 \mathrm{~h}$ values on an oral glucose tolerance test (OGTT) and overall mortality rates [2]. The Funagata study, conducted among residents of Funagata in Yamagata Prefecture, reported that impaired fasting glucose (IFG), defined as an elevation of fasting plasma glucose (FPG), but with a normal $2 \mathrm{~h}$ OGTT value, was not a risk factor for cardiovascular death [3]. Large-scale clinical studies, including the Action in Diabetes and Vascular Disease: Preterax and Diamicron MR Controlled Evaluation (ADVANCE) study [4], the Action to Control Cardiovascular Risk in Diabetes (ACCORD) study [5] and the Veterans Affairs Diabetes Trial (VADT) [6], showed that glycemic control based on glycated hemoglobin (HbA1c) levels alone does not reduce macrovascular disease. In addition to glycemic control using HbA1c as a marker, high-quality glycemic control focusing also on postprandial plasma glucose (PPG) levels is necessary.

Mitiglinide is a rapid- and short-acting insulinotropic sulfonylurea receptor (SUR) ligand, a benzylsuccinic acid derivative [7-9], which improves postprandial hyperglycemia in particular. In addition to mitiglinide, repaglinide and nateglinide are currently in clinical use as insulinotropic SUR ligands.

The present study evaluated the long-term efficacy and safety of adding mitiglinide (mitiglinide calcium hydrate (Glufast ${ }^{\circledR}$ tablets; Kissei Pharmaceutical Co. Ltd; Matsumoto, Japan) in Japanese patients with diabetes inadequately controlled with a dipeptidyl peptidase-4 (DPP-4) inhibitor or biguanide monotherapy. 


\section{MATERIALS AND METHODS}

This study was conducted between March 2011 and August 2012 at 13 medical institutions in Japan. All procedures were in accordance with the ethical standards of the responsible committee on human experimentation and with the Helsinki Declaration of 1975, as revised in 2000. Informed consent was obtained from all patients before inclusion into the study.

\section{Patients}

Subjects were adult T2DM patients without adequate glycemic control. Inclusion criteria were: $\mathrm{HbA1c} 6.9 \%$ to $<9.4 \%$; 1 or $2 \mathrm{~h}$ PPG $\geq 200 \mathrm{mg} / \mathrm{dL}$ on a meal tolerance test; and a fixed dosage and administration of either a DPP4 inhibitor or biguanide during at least 8 weeks before starting mitiglinide. Exclusion criteria were: patients with history of treatment with high-dose sulfonylurea (SU) within 24 weeks (168 days) of starting the observation period (week 4); patients requiring insulin therapy; patients with severe diabetic complications (including neuropathy, retinopathy, and nephropathy), severe liver disease, renal dysfunction, hypertension, or heart disease.

\section{Study Design}

This study was a multicenter, open label, longterm clinical trial. Patient eligibility was assessed during a 4-week observation period. Patients were seen as outpatients every 4 weeks after starting the study, and treatment was continued for 52 weeks.

During the 4-week observation period, a fixed dose of DPP-4 inhibitor or biguanide was administered orally. Eligible patients who met the inclusion criteria during the observation period then continued with the DPP-4 inhibitor or biguanide at the same dosage and additionally received mitiglinide $10 \mathrm{mg}$ three times a day orally (t.i.d PO) immediately (within $5 \mathrm{~min}$ ) before each meal. Thereafter, if after 12 weeks of continuous administration HbA1c did not reach the target value $[<7.4 \%$ if $\geq 7.4 \%$ at the start of administration (week 0 ) or $<6.9 \%$ if $<7.4 \%$ at week 0$]$, the dosage of mitiglinide could be increased to $20 \mathrm{mg}$ t.i.d from week 16 to attempt to gain further improvement. However, if the physician judged that mitiglinide $10 \mathrm{mg}$ t.i.d presented a safety problem, it could be reduced to $5 \mathrm{mg}$ t.i.d.

During both the observation and treatment periods, concomitant use of oral hypoglycemic agents (other than the study drug) and the use of insulin products were prohibited, whereas administration and dosage of drugs used from before the study for treatment of mild-tomoderate complications was not changed whenever possible.

Patient characteristics were examined at screening (week 4). HbA1c, FPG, 1,5anhydroglucitol (1,5-AG), hematology, blood chemistry and urinalysis values, body weight, and blood pressure were assessed every 4 weeks from week 4 to week 52. Postprandial plasma glucose and postprandial insulin (30 min, $1 \mathrm{~h}$, and $2 \mathrm{~h}$ after meal) were measured at weeks 4 , 16,28 , and 52. The 400-kcal meal tolerance test at week 4 was performed following administration of a DPP-4 inhibitor or biguanide, and from after week 16 by that of a DPP-4 inhibitor, or biguanide, in combination with mitiglinide.

\section{Study End Points}

Efficacy end points included: change in HbA1c, 1,5-AG, and FPG at each evaluation point from 
that measured at week 4 after addition of mitiglinide; therapeutic achievement rate of HbA1c target; and changes in postprandial plasma glucose or postprandial insulin level. Safety end points were incidence rates of adverse events including hypoglycemic episodes and adverse drug reactions. Weight and blood pressure were measured every 4 weeks throughout the study period.

\section{Target Sample Size}

The number of patients recruited was based on the "Guidelines for Clinical Evaluation of Oral Hypoglycemic Agents" published by the Ministry of Health, Labour and Welfare (MHLW) in 2010 [10]. The target sample size to evaluate 52 weeks of therapy in each baseline drug combined treatment group was set at $\geq 50$ patients (a total $\geq 100$ patients across the study).

\section{Statistical Analysis}

Efficacy end points included PPG (30 min, $1 \mathrm{~h}$, $2 \mathrm{~h}$ ), postprandial insulin (30 min, $1 \mathrm{~h}, 2 \mathrm{~h}$ ), HbA1c, FPG, 1,5-AG, and fasting insulin. For these end points, mean and standard deviation (SD) of the changes at each evaluation time point (value at each evaluation time point - value at baseline) were calculated. Changes over time are shown and compared with baseline using the one-sample $t$ test. The HbA1c target achievement rate was evaluated at weeks 12, 28, 40, 52, and/or final evaluation. The HbA1c target achievement rate was calculated as the percentage of patients who achieved an HbA1c of $<7.0 \%$ at weeks 12,28 , 40,52 , and/or final evaluation among patients with an HbA1c $\geq 7.0 \%$ at week 0 . The insulinogenic index is shown as the median value at each evaluation time point. Safety end points included adverse events and adverse drug reactions (all and hypoglycemia), clinical laboratory tests and physiological parameters. The presence or absence of adverse events and adverse drug reactions (all and hypoglycemia) was assessed in each patient, and the incidence and two-sided 95\% confidence intervals were calculated. The incidence and types of adverse events and adverse drug reactions overall and by organ system class were calculated. Totals were calculated for each combined treatment group.

\section{RESULTS}

\section{Analyzed Cases}

Figure 1 shows the patient characteristics. A total of 191 patients consented to study participation. After a 4-week observation period with administration of DPP-4 inhibitors or biguanides as the baseline drug, mitiglinide was administered to 136 patients who were judged as being eligible for the study (DPP-4 inhibitor CTG, 67 patients; biguanide CTG, 69 patients). Baseline drugs included sitagliptin in 26 patients, vildagliptin in 18, alogliptin in 23 , metformin in 66, and buformin in 3.

Treatment was discontinued in 26 patients (DPP-4 inhibitor CTG, 9; biguanide CTG, 17) during the study. The reasons for discontinuation from the study were as follows: for DPP-4 inhibitor CTG-adverse events in two patients, inadequate response in five, and other reason in three patients ("at request of patient," "needed to discontinue baseline drug," and "could not return for outpatient visit"); and for biguanide CTGadverse events were reported in 4 patients, inadequate response in 12, and other reason in 2 patients ("at request by patient" in both). One patient in both of the DPP-4 inhibitor CTG and biguanide CTG had two reasons for 


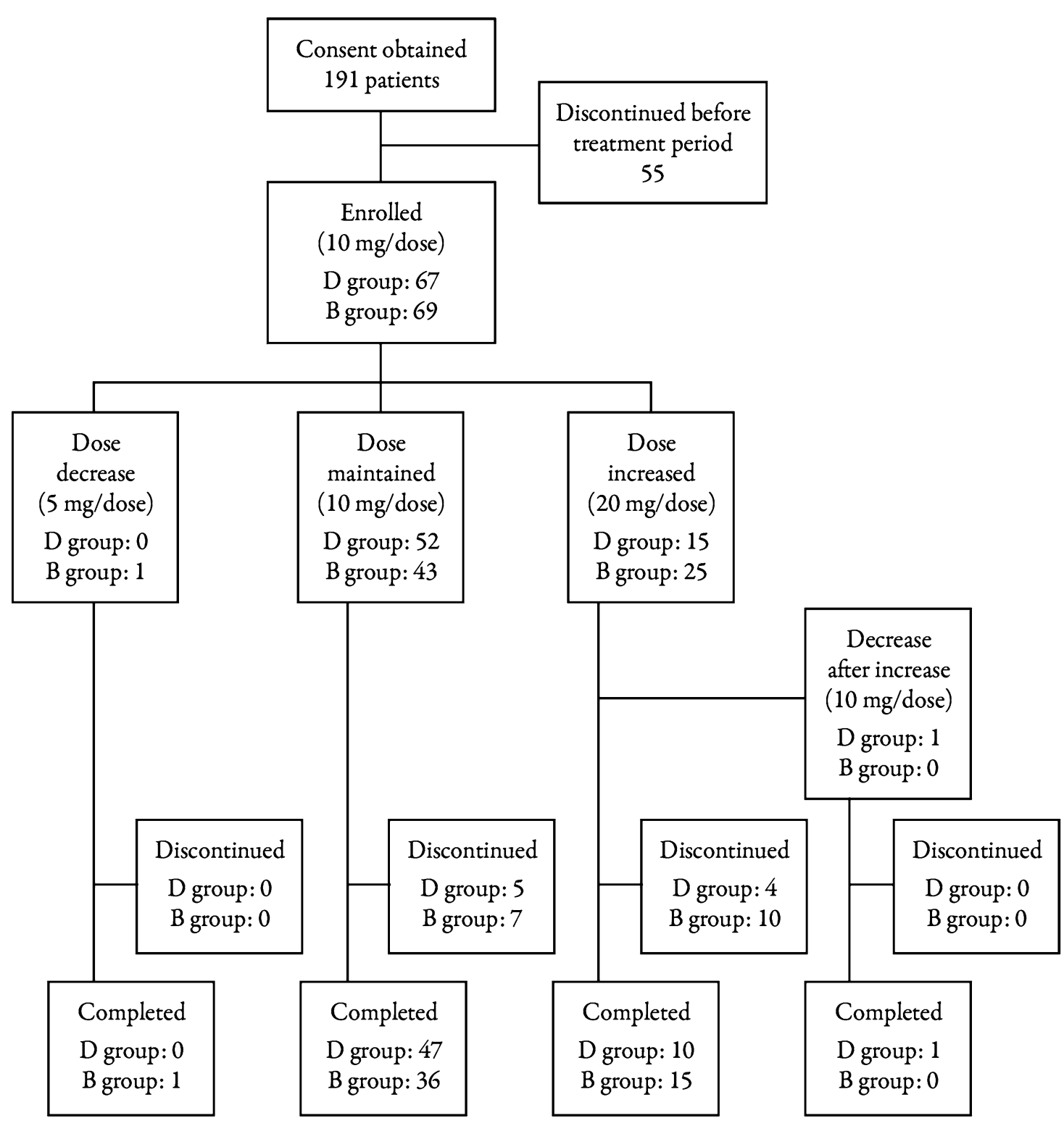

Fig. 1 Patient characteristics. D group DPP-4 inhibitor combined treatment group, $B$ group biguanide combined treatment group

discontinuation (adverse event and patient request).

\section{Patient Characteristics}

A total of 136 patients received mitiglinide (DPP-4 inhibitor CTG, 67; biguanide CTG, 69), but after mitiglinide was started, one patient in the biguanide CTG was excluded because of early discontinuation and no evaluable HbA1c. Therefore, the full analysis set included 135 patients (DPP-4 inhibitor CTG, 67; biguanide CTG, 68). Table 1 shows the patient characteristics.

Baseline values (mean $\pm \mathrm{SD}$ ) for the primary efficacy end points of HbA1c, FPG, and 2 h PPG 
Table 1 Patient characteristics

\begin{tabular}{llll}
\hline Characteristics & Total $(\boldsymbol{n}=\mathbf{1 3 5})$ & $\begin{array}{l}\text { Mitiglinide/DPP-4 } \\
\text { inhibitors }(\boldsymbol{n}=\mathbf{6 7})\end{array}$ & $\begin{array}{l}\text { Mitiglinide/ } \\
\text { biguanides }(\boldsymbol{n}=\mathbf{6 8})\end{array}$ \\
\hline Male, $n(\%)$ & $96(71.1)$ & $46(68.7)$ & $50(73.5)$ \\
Age $($ years $)$ & $58.6 \pm 11.1$ & $60.3 \pm 10.6$ & $56.9 \pm 11.5$ \\
BMI $\left(\mathrm{kg} / \mathrm{m}^{2}\right)$ & $24.85 \pm 4.50$ & $24.30 \pm 4.71$ & $25.40 \pm 4.25$ \\
Duration of disease (years) & $7.6 \pm 5.6$ & $6.7 \pm 5.4$ & $8.5 \pm 5.8$ \\
HOMA-R & $2.97 \pm 2.86$ & $2.95 \pm 3.10$ & $3.00 \pm 2.62$ \\
HbAlc at 0 weeks $(\%)$ & $7.49 \pm 0.60$ & $7.47 \pm 0.54$ & $7.50 \pm 0.66$ \\
FPG at 0 weeks $(\mathrm{mg} / \mathrm{dL})$ & $148.7 \pm 27.4$ & $153.7 \pm 27.1$ & $143.8 \pm 27.0$ \\
PPG 30 min at -4 weeks $(\mathrm{mg} / \mathrm{dL})$ & $228.1 \pm 37.6$ & $229.2 \pm 36.9$ & $227.1 \pm 38.6$ \\
PPG 1 h at -4 weeks $(\mathrm{mg} / \mathrm{dL})$ & $268.7 \pm 39.7$ & $269.2 \pm 39.4$ & $268.2 \pm 40.3$ \\
PPG 2 h at -4 weeks $(\mathrm{mg} / \mathrm{dL})$ & $245.6 \pm 49.5$ & $248.1 \pm 45.9$ & $243.3 \pm 53.0$ \\
Fasting insulin at 0 weeks $(\mu \mathrm{U} / \mathrm{mL})$ & $7.90 \pm 6.68$ & $7.49 \pm 6.55$ & $8.32 \pm 6.82$ \\
Postprandial insulin $30 \mathrm{~min}$ at -4 weeks $(\mu \mathrm{U} / \mathrm{mL})$ & $21.66 \pm 13.84$ & $20.08 \pm 11.73$ & $23.22 \pm 15.58$ \\
Postprandial insulin $1 \mathrm{~h}$ at $-4 \mathrm{w}$ weeks $(\mu \mathrm{U} / \mathrm{mL})$ & $31.78 \pm 21.86$ & $28.73 \pm 18.22$ & $34.79 \pm 24.71$ \\
Postprandial insulin $2 \mathrm{~h}$ at -4 weeks $(\mu \mathrm{U} / \mathrm{mL})$ & $32.14 \pm 21.65$ & $29.73 \pm 20.25$ & $34.52 \pm 22.85$ \\
\hline
\end{tabular}

Values are mean $\pm \mathrm{SD}$

$B M I$ body mass index, $F P G$ fasting plasma glucose, $H b 1 A c$ glycated hemoglobin, $H O M A$-R homeostasis model assessment ratio, $P P G$ postprandial plasma glucose

were: DPP-4 inhibitor CTG $7.47 \pm 0.54 \%$, $153.7 \pm 27.1 \mathrm{mg} / \mathrm{dL}$, and $248.1 \pm 45.9 \mathrm{mg} / \mathrm{dL}$, respectively; and biguanide CTG $7.50 \pm 0.66 \%$, $143.8 \pm 27.0 \mathrm{mg} / \mathrm{dL}$, and $243.3 \pm 53.0 \mathrm{mg} / \mathrm{dL}$, respectively. These patients with type 2 diabetes in the DPP-4 inhibitor CTG and biguanide CTG had inadequate glycemic control and were enrolled in the study. BMI distribution before starting treatment (baseline) showed a higher percentage of obese patients (BMI $\geq 25 \mathrm{~kg} / \mathrm{m}^{2}$ ) in the biguanide CTG than in the DPP-4 inhibitor CTG (DPP-4 inhibitor CTG, 31.3\%; biguanide CTG, $48.5 \%$ ).

\section{Efficacy}

In both the DPP-4 inhibitor CTG and the biguanide CTG, a comparison of $30 \mathrm{~min}, 1 \mathrm{~h}$, and $2 \mathrm{~h}$ PPG values between baseline and each evaluation time point (weeks 16, 28 and 52, and final evaluation) showed significant improvement (all with $P<0.001$, Table 2 ). In addition, FPG during early combined treatment (weeks 12-20) showed a significant improvement compared with baseline. Subsequently, in both cohorts there was a deterioration, followed by a trend toward improvement from week 40 until completion of mitiglinide administration (data not shown).

In both the DPP-4 inhibitor CTG and biguanide CTG, postprandial insulin levels at each evaluation time point confirmed significant stimulation of insulin secretion at $30 \mathrm{~min}$ and $1 \mathrm{~h}$ postprandially (Fig. 2). Fasting insulin levels did not substantially change throughout the study period. 
Table 2 Change in postprandial plasma glucose

\begin{tabular}{|c|c|c|c|c|c|c|}
\hline Item & Baseline drug & Time & Number & Change & SD & $P$ value \\
\hline \multirow[t]{8}{*}{ PPG $30 \mathrm{~min}(\mathrm{mg} / \mathrm{dL})$} & \multirow[t]{4}{*}{ DPP-4 inhibitors } & 16 weeks & 65 & -38.5 & 34.9 & $<0.001$ \\
\hline & & 28 weeks & 64 & -28.0 & 32.9 & $<0.001$ \\
\hline & & 52 weeks & 58 & -37.9 & 33.4 & $<0.001$ \\
\hline & & Final & 65 & -34.8 & 35.5 & $<0.001$ \\
\hline & \multirow[t]{4}{*}{ Biguanides } & 16 weeks & 67 & -28.0 & 37.2 & $<0.001$ \\
\hline & & 28 weeks & 65 & -23.0 & 46.2 & $<0.001$ \\
\hline & & 52 weeks & 53 & -27.6 & 39.1 & $<0.001$ \\
\hline & & Final & 68 & -22.4 & 39.2 & $<0.001$ \\
\hline \multirow[t]{8}{*}{ PPG 1 h (mg/dL) } & \multirow[t]{4}{*}{ DPP-4 inhibitors } & 16 weeks & 65 & -51.4 & 39.8 & $<0.001$ \\
\hline & & 28 weeks & 64 & -45.4 & 40.0 & $<0.001$ \\
\hline & & 52 weeks & 58 & -49.7 & 37.0 & $<0.001$ \\
\hline & & Final & 65 & -46.6 & 38.7 & $<0.001$ \\
\hline & \multirow[t]{4}{*}{ Biguanides } & 16 weeks & 67 & -42.3 & 38.1 & $<0.001$ \\
\hline & & 28 weeks & 65 & -40.0 & 48.4 & $<0.001$ \\
\hline & & 52 weeks & 53 & -37.1 & 44.7 & $<0.001$ \\
\hline & & Final & 68 & -33.0 & 44.2 & $<0.001$ \\
\hline \multirow[t]{8}{*}{ PPG 2 h (mg/dL) } & \multirow[t]{4}{*}{ DPP-4 inhibitors } & 16 weeks & 65 & -51.8 & 50.7 & $<0.001$ \\
\hline & & 28 weeks & 64 & -50.5 & 51.9 & $<0.001$ \\
\hline & & 52 weeks & 58 & -49.2 & 46.7 & $<0.001$ \\
\hline & & Final & 65 & -46.3 & 47.0 & $<0.001$ \\
\hline & \multirow[t]{4}{*}{ Biguanides } & 16 weeks & 67 & -42.3 & 46.7 & $<0.001$ \\
\hline & & 28 weeks & 65 & -42.3 & 56.2 & $<0.001$ \\
\hline & & 52 weeks & 53 & -39.1 & 53.5 & $<0.001$ \\
\hline & & Final & 68 & -36.0 & 51.6 & $<0.001$ \\
\hline
\end{tabular}

$P$ value: one-sided $t$ test [vs. before treatment with mitiglinide ( -4 weeks)]

$D P P-4$ dipeptidyl peptidase-4, $P P G$ postprandial plasma glucose

Figure 3 shows the changes in the insulinogenic index in the DPP-4 inhibitor CTG and biguanide CTG. The insulinogenic index (IGI) at week 4 (when patients were treated with a DPP-4 inhibitor or biguanide as monotherapy) was low at 0.17 and 0.15 (median values), respectively. After combined treatment with mitiglinide (at final evaluation), the IGI was
0.59 in the DPP-4 inhibitor CTG and 0.47 in the biguanide CTG. The addition of mitiglinide improved early insulin secretion. In both the DPP-4 inhibitor CTG and biguanide CTG, 1,5-AG was significantly improved at all evaluation time points as compared to baseline (data not shown).

Table 3 shows the changes in HbA1c. Table 4 shows the HbA1c $<7.0 \%$ achievement rates at 

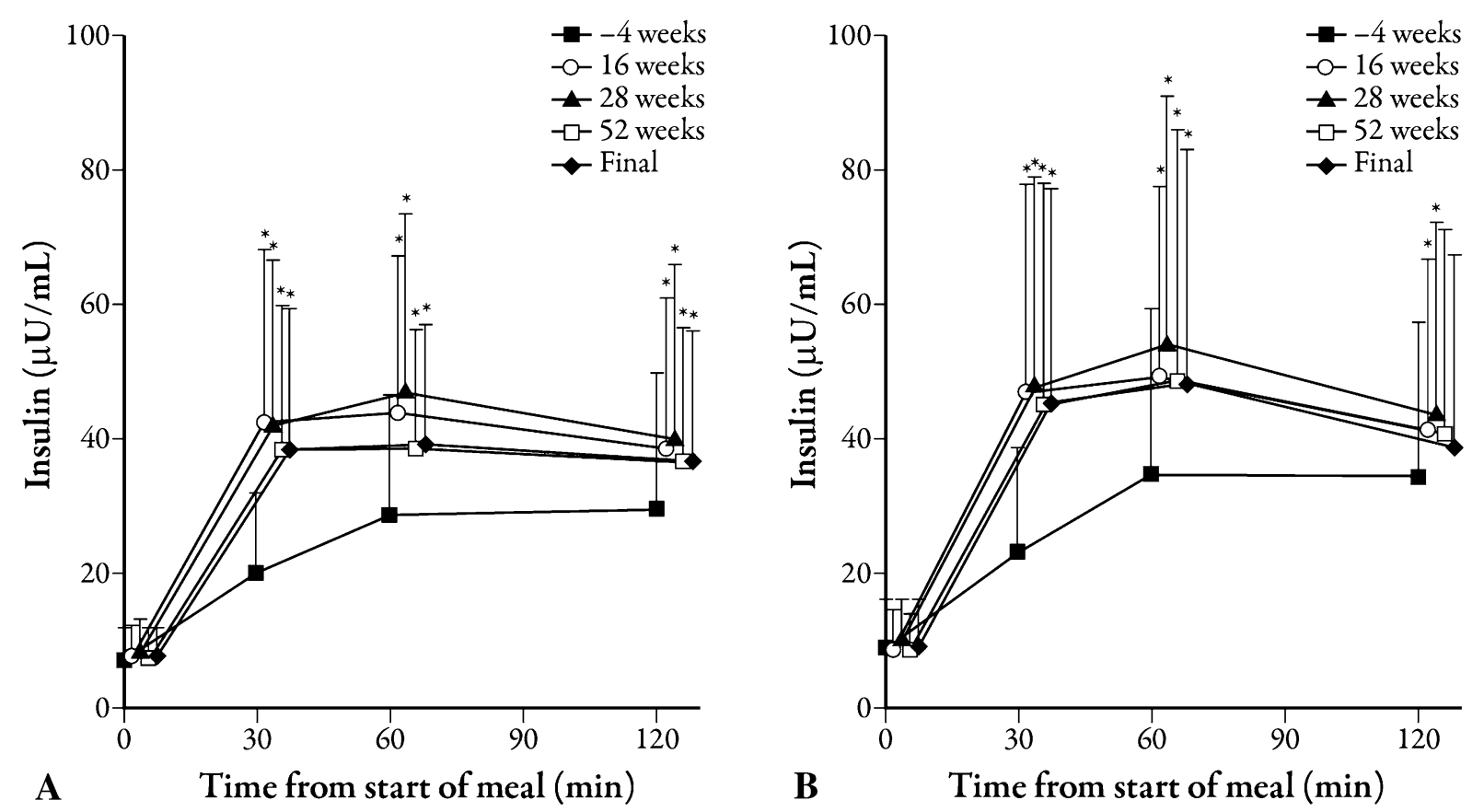

Fig. 2 Change in postprandial insulin secretion (mean \pm SD). a DPP-4 inhibitor combined treatment group, b biguanide combined treatment group ${ }^{*} P<0.05$ vs. -4 weeks
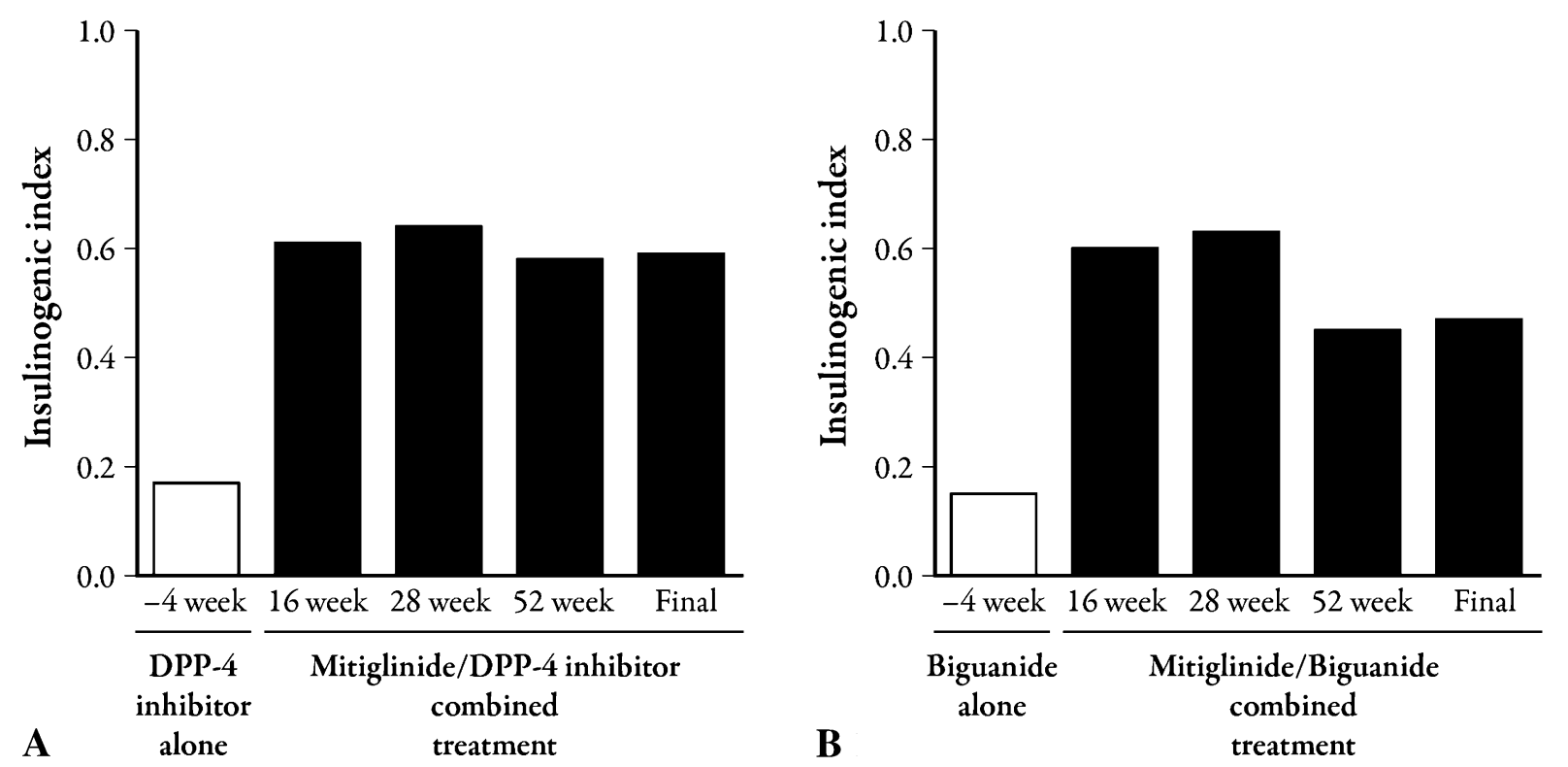

Fig. 3 Insulinogenic index (median value). Insulinogenic index: $\Delta$ insulin $(30 \mathrm{~min}-0 \mathrm{~min}) / \Delta$ glucose $(30 \mathrm{~min}-0 \mathrm{~min})$. a DPP-4 inhibitor combined treatment group, b biguanide combined treatment group

weeks 12, 28, 40 and 52, and at final evaluation. HbA1c levels, compared to baseline, were significantly lower at all evaluation time points in the DPP-4 inhibitor CTG and were significantly lower at all evaluation time points, except week 40 and final evaluation, in the 
Table 3 Changes in HbAlc

\begin{tabular}{|c|c|c|c|c|c|c|c|c|}
\hline \multirow[t]{2}{*}{ Time } & \multicolumn{4}{|c|}{ Mitiglinide/DPP-4 inhibitors } & \multicolumn{4}{|c|}{ Mitiglinide/biguanides } \\
\hline & Number & Change & SD & $P$ value & Number & Change & SD & $P$ value \\
\hline 4 weeks & 67 & -0.31 & 0.29 & $<0.001$ & 68 & -0.23 & 0.26 & $<0.001$ \\
\hline 8 weeks & 66 & -0.55 & 0.37 & $<0.001$ & 68 & -0.39 & 0.41 & $<0.001$ \\
\hline 12 weeks & 66 & -0.60 & 0.46 & $<0.001$ & 68 & -0.41 & 0.55 & $<0.001$ \\
\hline 16 weeks & 65 & -0.54 & 0.49 & $<0.001$ & 67 & -0.40 & 0.49 & $<0.001$ \\
\hline 20 weeks & 65 & -0.56 & 0.56 & $<0.001$ & 67 & -0.44 & 0.57 & $<0.001$ \\
\hline 24 weeks & 64 & -0.58 & 0.60 & $<0.001$ & 65 & -0.44 & 0.59 & $<0.001$ \\
\hline 28 weeks & 64 & -0.47 & 0.55 & $<0.001$ & 65 & -0.34 & 0.60 & $<0.001$ \\
\hline 32 weeks & 63 & -0.46 & 0.56 & $<0.001$ & 63 & -0.27 & 0.64 & 0.001 \\
\hline 36 weeks & 63 & -0.34 & 0.59 & $<0.001$ & 60 & -0.19 & 0.59 & 0.015 \\
\hline 40 weeks & 61 & -0.36 & 0.58 & $<0.001$ & 60 & -0.14 & 0.61 & 0.071 \\
\hline 44 weeks & 60 & -0.39 & 0.61 & $<0.001$ & 58 & -0.19 & 0.62 & 0.021 \\
\hline 48 weeks & 59 & -0.40 & 0.59 & $<0.001$ & 56 & -0.22 & 0.60 & 0.007 \\
\hline 52 weeks & 58 & -0.45 & 0.69 & $<0.001$ & 53 & -0.28 & 0.63 & 0.001 \\
\hline Final & 67 & -0.37 & 0.69 & $<0.001$ & 68 & -0.13 & 0.76 & 0.154 \\
\hline
\end{tabular}

Units: \%

$P$ value: one-sided $t$ test [vs. before treatment with mitiglinide (week 0 )]

$D D P-4$ dipeptidyl dipeptidase-4, HblAc glycated hemoglobin

Table 4 HbAlc $<7.0 \%$ achievement rate

\begin{tabular}{lllll}
\hline Group & $\begin{array}{l}\text { Time } \\
(\text { weeks })\end{array}$ & Number & $\boldsymbol{n}$ & \% \\
\hline Mitiglinide/DPP-4 & 12 & 53 & 30 & 56.6 \\
$\begin{array}{llll}\text { inhibitors } \\
\text { 28 }\end{array}$ & 51 & 25 & 49.0 \\
& 40 & 48 & 20 & 41.7 \\
& 52 & 45 & 28 & 62.2 \\
& Final & 54 & 31 & 57.4 \\
Mitiglinide/biguanides & 12 & 48 & 21 & 43.8 \\
& 28 & 46 & 19 & 41.3 \\
& 40 & 43 & 12 & 27.9 \\
& 52 & 36 & 13 & 36.1 \\
& Final & 48 & 14 & 29.2 \\
\hline
\end{tabular}

DPP-4 dipeptidyl peptidase-4, HblAc glycated hemoglobin biguanide CTG. The HbA1c $<7.0 \%$ achievement rate throughout the study period was $41.7-62.2 \%$ in the DPP-4 inhibitor CTG and $27.9-43.8 \%$ in the biguanide CTG.

\section{Safety}

Table 5 shows the incidence of adverse events and adverse drug reactions, including hypoglycemia. The incidence of adverse events was $71.6 \%$ (48/67 patients) in the DPP-4 inhibitor CTG and 82.6\% (57/69 patients) in the biguanide CTG. Among adverse events, the incidence of hypoglycemia (adverse events) was $3.0 \%$ (2/67 patients) in the DPP-4 inhibitor CTG and $2.9 \%$ (2/69 patients) in the biguanide CTG. 
Adverse drug reactions for which a causal relationship to mitiglinide could not be excluded occurred in $6.0 \%$ (4/67 patients) in the DPP-4 inhibitor CTG and $5.8 \%$ (4/69 patients) in the biguanide CTG. Hypoglycemia in all cases was judged as an adverse drug reaction by a physician.

Adverse events with an incidence $\geq 5 \%$ in the DPP-4 inhibitor CTG included nasopharyngitis, 25.4\% (17/67); pharyngitis, 9.0\% (6/67); upper respiratory tract infection, $7.5 \% \quad(5 / 67)$; arthralgia, 6.0\% (4/67); back pain, 6.0\% (4/67); and $\gamma$-glutamyltransferase increase, $6.0 \%(4 / 67)$. Adverse events with an incidence $\geq 5 \%$ in the biguanide CTG included nasopharyngitis, 43.5\% (30/69); bronchitis, $11.6 \% \quad(8 / 69)$; $\gamma$-glutamyltransferase increase $10.1 \% \quad(7 / 69)$; upper respiratory tract infection, $7.2 \%(5 / 69)$ alanine aminotransferase increase, 7.2\% (5/69); white blood cell count increase, 7.2\% (5/69); dental caries, 5.8\% (4/69); and blood urine presence, $5.8 \%$ (4/69) (Table 6).

The number of adverse events by severity was: DPP-4 inhibitor CTG-mild 128, moderate 5 , and severe 0 events; biguanide CTG-mild 185 , moderate 5 , and severe 6 events. Most adverse events were mild or moderate. A causal relationship with mitiglinide was excluded for all the six severe events in the biguanide CTG. In addition, all hypoglycemic events were mild.

One serious adverse event occurred in one patient in the DPP-4 inhibitor CTG: large intestine carcinoma. Nine serious adverse events occurred among five patients in the biguanide CTG: prostate cancer, acute myocardial infarction, brain contusion, skull fracture, traumatic lung injury, rib fracture, lumbar vertebral fracture, colonic polyp, and large intestine carcinoma. A causal relationship with mitiglinide was excluded for all of these serious adverse events. No deaths occurred in the study.

Figure 4 shows the changes in weight in the DPP-4 inhibitor CTG and biguanide CTG. Weight in the DPP-4 inhibitor CTG was: week $0, \quad 64.62 \pm 13.97 \mathrm{~kg} \quad($ mean $\pm \mathrm{SD}) ;$ week 16, $65.42 \pm 14.35 \mathrm{~kg}$; week 28, $66.04 \pm 14.64 \mathrm{~kg}$; week $40, \quad 65.75 \pm 15.12 \mathrm{~kg}$, week 52 , $65.17 \pm 14.89 \mathrm{~kg} ; \quad$ and final evaluation, $65.59 \pm 14.37 \mathrm{~kg}$. Weight in the biguanide CTG was: week $0,70.23 \pm 15.30 \mathrm{~kg}$; week 16 , $70.81 \pm 15.36 \mathrm{~kg}$; week $28, \quad 70.45 \pm 14.98 \mathrm{~kg}$; week $40, \quad 71.36 \pm 14.39 \mathrm{~kg}$, week 52 , $69.42 \pm 13.52 \mathrm{~kg}$; and final evaluation, $70.57 \pm 15.06 \mathrm{~kg}$. Weight increased slightly during the study period, but by study

Table 5 Incidence of adverse events and adverse drug reactions

\begin{tabular}{lccc}
\hline & $\begin{array}{c}\text { Mitiglinide/DPP-4 } \\
\text { inhibitors }(n=67)\end{array}$ & $\begin{array}{l}\text { Mitiglinide/biguanides } \\
(n=69)\end{array}$ & Total $(n=136)$ \\
\hline Adverse events & $71.6(59.3,82.0)$ & $82.6(71.6,90.7)$ & $77.2(69.2,84.0)$ \\
All & $3.0(0.4,10.4)$ & $2.9(0.4,10.1)$ & $2.9(0.8,7.4)$ \\
Hypoglycemia symptoms & $6.0(1.7,14.6)$ & $5.8(1.6,14.2)$ & $5.9(2.6,11.3)$ \\
Adverse drug reactions & $3.0(0.4,10.4)$ & $2.9(0.4,10.1)$ & $2.9(0.8,7.4)$ \\
All & & & \\
Hypoglycemia symptoms & & & \\
\hline
\end{tabular}

Data are incidence rate and $95 \%$ confidence interval

$D P P-4$ dipeptidyl peptidase- 4 
Table 6 Adverse events and adverse drug reactions with an incidence of $\geq 5 \%$

\begin{tabular}{|c|c|c|c|c|c|c|c|c|}
\hline & \multicolumn{4}{|c|}{ Adverse event } & \multicolumn{4}{|c|}{ Adverse drug reaction } \\
\hline & \multicolumn{2}{|c|}{$\begin{array}{l}\text { Mitiglinide/DPP- } \\
4 \text { inhibitors } \\
(n=67)\end{array}$} & \multicolumn{2}{|c|}{$\begin{array}{l}\text { Mitiglinide/ } \\
\text { biguanides } \\
(n=69)\end{array}$} & \multicolumn{2}{|c|}{$\begin{array}{l}\text { Mitiglinide/DPP- } \\
4 \text { inhibitors } \\
(n=67)\end{array}$} & \multicolumn{2}{|c|}{$\begin{array}{c}\text { Mitiglinide/ } \\
\text { biguanides } \\
(n=69)\end{array}$} \\
\hline & $\bar{n}$ & $\%$ & $\bar{n}$ & $\%$ & $\bar{n}$ & $\%$ & $\bar{n}$ & $\%$ \\
\hline Bronchitis & 2 & 3.0 & 8 & 11.6 & 0 & 0.0 & 0 & 0.0 \\
\hline Nasopharyngitis & 17 & 25.4 & 30 & 43.5 & 0 & 0.0 & 0 & 0.0 \\
\hline Pharyngitis & 6 & 9.0 & 2 & 2.9 & 0 & 0.0 & 0 & 0.0 \\
\hline Upper respiratory tract inflammation & 5 & 7.5 & 5 & 7.2 & 0 & 0.0 & 0 & 0.0 \\
\hline Dental caries & 0 & 0.0 & 4 & 5.8 & 0 & 0.0 & 0 & 0.0 \\
\hline Arthralgia & 4 & 6.0 & 1 & 1.4 & 0 & 0.0 & 0 & 0.0 \\
\hline Back pain & 4 & 6.0 & 1 & 1.4 & 0 & 0.0 & 0 & 0.0 \\
\hline Alanine aminotransferase increase & 0 & 0.0 & 5 & 7.2 & 0 & 0.0 & 0 & 0.0 \\
\hline$\gamma$-glutamyltransferase increase & 4 & 6.0 & 7 & 10.1 & 0 & 0.0 & 1 & 1.4 \\
\hline Blood urine present & 0 & 0.0 & 4 & 5.8 & 0 & 0.0 & 0 & 0.0 \\
\hline White blood cell count increase & 3 & 4.5 & 5 & 7.2 & 0 & 0.0 & 0 & 0.0 \\
\hline
\end{tabular}

$D P P-4$ dipeptidyl peptidase-4

completion tended to return to baseline levels. Blood pressure showed no significant changes in either the DPP-4 inhibitor CTG or biguanide CTG.

\section{DISCUSSION}

Mitiglinide, a rapid- and short-acting insulinotropic agent, has been used to improve postprandial hyperglycemia in T2DM [11-13]. However, to date, sufficient evidence has not been established for combined treatment with a DPP-4 inhibitor or biguanide. In this study, we investigated the efficacy and safety of mitiglinide for use in combined treatment in Japanese patients with T2DM experiencing inadequate glycemic control with DPP-4 inhibitors or biguanides monotherapy.

With regard to efficacy, in both the DPP-4 inhibitor CTG and biguanide CTG, the addition of mitiglinide significantly stimulated early postprandial insulin secretion, with significant improvement in PPG $(30 \mathrm{~min}, 1 \mathrm{~h}$, and $2 \mathrm{~h}$ values) throughout the study period. In general, IGI is often $\leq 0.4$ during a 75 -g OGTT in T2DM patients [14]. In this study, the baseline IGI was as low as 0.15-0.17 (median value), but after mitiglinide administration many patients had an IGI $\geq 0.4$ during a 400-kcal meal tolerance test. These results confirmed an improvement in early postprandial insulin secretion, a characteristic of mitiglinide, even in combined treatment with a DPP-4 inhibitor or biguanide.

A meal tolerance test to evaluate PPG values is time consuming for patients and requires frequent collection of blood samples. Therefore, when compared with HbA1c and FPG, testing for PPG is performed in few patients. However, glycemic control based on HbA1c as a marker alone may not 

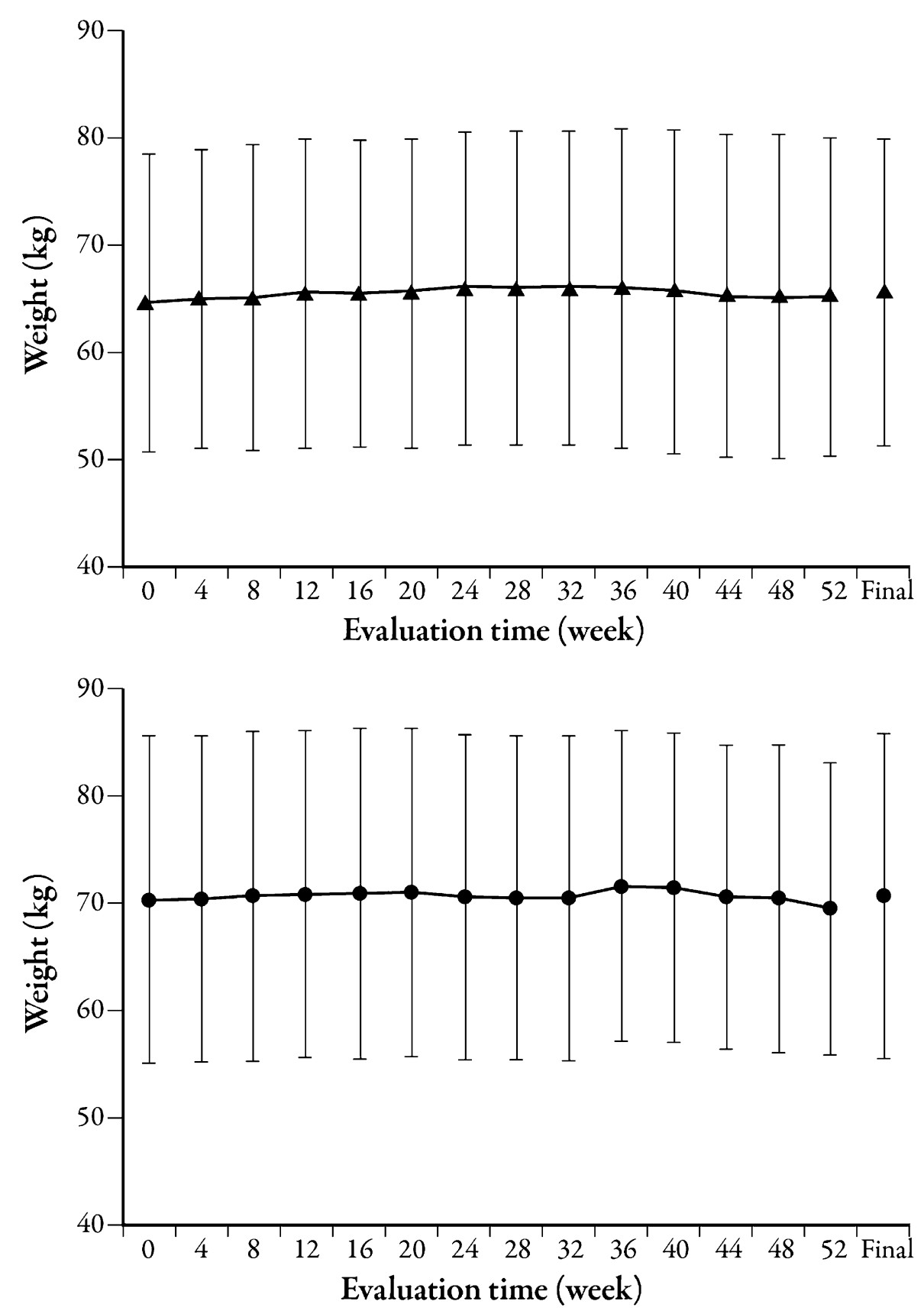

Fig. 4 Change in weight (mean \pm SD). Top DPP-4 inhibitor combined treatment group. Bottom biguanide combined treatment group

reduce the incidence of macrovascular complications [4-6]. To manage high-quality glycemic control in T2DM patient, it is necessary once again to recognize the clinical importance of improving postprandial hyperglycemia.
Regarding HbA1c as a marker of overall glycemic control, an HbA1c of $<7.0 \%$ has been established as a target in terms of preventing diabetic complications [14]. In this study, at the time of final evaluation, the HbA1c $<7.0 \%$ 
achievement rate was $57.4 \%$ in the DPP-4 inhibitor CTG and $29.2 \%$ in the biguanide CTG. Although this rate was somewhat low in the biguanide CTG when compared with the DPP-4 inhibitor CTG, the addition of mitiglinide enabled a certain amount of patients to reach this target goal.

In both the DPP-4 inhibitor CTG and biguanide CTG, HbA1c transiently increased after week 28, reached a peak at week 40 , and then again improved. The reason was probably a seasonal fluctuation in HbA1c levels, as clinically reported in Japan and overseas [1214]. These clinical reports have described increased HbA1c levels from the autumn to before spring, with fluctuations of about $0.2-0.3 \%$. In this study, weeks $24-40$ in many patients corresponded to the period from autumn to before spring. Considering that the increase in $\mathrm{HbA1c}$ was also about $0.2-0.3 \%$, the fluctuation in this study was probably similar to the seasonal fluctuations reported elsewhere [15-17]. These findings again highlight the importance of not only drug therapy, but also dietary and exercise therapy in T2DM.

With regard to safety, the incidence of hypoglycemia, which is generally a concern when using oral glucose-lowering drugs, was $3.0 \%$ (2/67 patients) in the DPP-4 inhibitor CTG and $2.9 \%$ (2/69 patients) in the biguanide CTG. Thus, the incidence of hypoglycemia was low, and all hypoglycemic symptoms were mild. Body weight increased slightly during the study in both the DPP-4 inhibitor CTG and biguanide CTG, but by completion of treatment tended to revert to baseline levels. This may also be a seasonal fluctuation similar to glycemic control.

This study has two important limitations. Firstly, it was conducted under open label design with no control arm, and therefore it was not possible to eliminate all confounding factors. Secondly, in our study, the variety of DPP-4 inhibitors and biguanides used was limited; the DPP-4 inhibitors were sitagliptin, alogliptin and vildagliptin only, and biguanide buformin was used in only three cases. Therefore, interpretation of our findings requires caution until further studies can be conducted.

\section{CONCLUSION}

The combination of mitiglinide with DPP-4 inhibitors or biguanides improved postprandial hyperglycemia and $\mathrm{HbA1c}$, as a marker of overall glycemic control, without increasing risk to safety. This therapy is a clinically promising therapeutic strategy for T2DM.

\section{ACKNOWLEDGMENTS}

The authors would like to thank all the following investigators for their assistance with this study: Takeshi Osonoi, Miyoko Saito, Atsuko Tamasawa, Hidenori Ishida, Yusuke Osonoi, Naka Kinen Clinic; Hiroshi Ohashi, Oyama East Clinic; Takaichi Miyakawa, Hitomi Fujii, Yuko Watanabe, Kazuo Nakajima, Makoto Hasegawa, Tama-center Mirai Clinic; Satoko Otsuka, Yoshihisa Otsuka, Gonohashi Tower Clinic; Kazuhiro Hosokawa, Hosokawa Clinic; Kiyokazu Matoba, Raishi Ichikawa, Matoba Diabetes Clinic; Tsutomu Hayashi, Hayashi Diabetes and Metabolism Clinic; Shinya Fujii, Fujii Clinic; Shigeaki Morizono, Iryouhoujin Aimeikai Morizononaika; Nobuyuki Abe, Setsuko Abe, Rie Abe, Katsushige Abe, Yoko Abe, Kazuyuki Hamaguchi, Internal Medicine Abe Clinic; Naoki Itabashi, Itabashi Diabetic Medicine and Dermatology Clinic; Aizan Hirai, Shigeki Imamura, Narihiro Furugaki, Eiji 
Hayashi, Akiko Murata, Takao Namiki, Chiba Prefectural Togane Hospital; Michio Nakagawa, Katsuhiko Enomoto, Matsumoto Nakagawa Hospital. This study was designed and funded by Kissei Pharmaceutical Co., Ltd. The article processing charges were also funded by Kissei Pharmaceutical Co., Ltd. Springer Japan KK Springer Healthcare Business Unit provided assistance with English language editing and preparation of the manuscript for submission. This assistance was funded by Kissei Pharmaceutical Co., Ltd. Dr Kaku is the guarantor for this paper and takes responsibility for the work as a whole.

Conflict of interest. K. Kaku has received research funding, consultancy fees, or lecture fees from Astellas, AstraZeneca, MSD, DaiichiSankyo, Kissei, Bristol-Myers Squibb, Dainippon-Sumitomo, Novartis, Novo Nordisk, Sanofi, Sanwa, and Takeda Pharmaceutical Company Limited. There are no other potential conflicts of interest relevant to this article. N. Inagaki has received research funding or consultancy fees or lecture fees from Astellas, Daiichi-Sankyo, Dainippon-Sumitomo Pharma, Eli Lily Japan, Japan Diabetes Foundation, JT, Kyowa Kirin, Mitsubishi Tanabe Pharma, MSD, Nippon Boehringer Ingelheim, Novartis Pharma, Roche Diagnostics, Sanofi, Shiratori Pharmaceutical, and Takeda. N. Kobayashi is an employee of Kissei Pharmaceutical Co., Ltd.

Compliance with ethics guidelines. All procedures were in accordance with the ethical standards of the responsible committee on human experimentation and with the Helsinki Declaration of 1975, as revised in 2000. Informed consent was obtained from all patients before inclusion in the study.
Open Access. This article is distributed under the terms of the Creative Commons Attribution Noncommercial License which permits any noncommercial use, distribution, and reproduction in any medium, provided the original author(s) and the source are credited.

\section{REFERENCES}

1. Ceriello A. Impaired glucose tolerance and cardiovascular disease: the possible role of postprandial hyperglycemia. Am Heart J. 2004;147:803-7.

2. The DECODE study group. Glucose tolerance and mortality: comparison of WHO and American Diabetic Association diagnostic criteria. Lancet. 1999;354:617-21.

3. Tominaga M, Eguchi H, Manaka H, Igarashi K, Kato $\mathrm{T}$, Sekikawa A. Impaired glucose tolerance is a risk factor for cardiovascular disease, but not impaired fasting glucose. Diabetes Care. 1999;22:920-4.

4. The ADVANCE collaborative group. Intensive blood glucose control and vascular outcomes in patients with type 2 diabetes. N Engl J Med. 2008;358: 2560-72.

5. The action to control cardiovascular Risk in Diabetes Study Group. Effects of intensive glucose lowering in type 2 diabetes. $\mathrm{N}$ Engl J Med. 2008;358:2545-59.

6. Duckworth W, Abraira C, Moritz T, et al. Glucose control and vascular complications in veterans with type 2 diabetes. N Engl J Med. 2009;360:129-39.

7. Ohnota H, Koizumi T, Tsutsumi N, Kobayashi M, Inoue S, Sato F. Novel rapid- and short-acting hypoglycemic agent, a calcium (2s)-2-benzyl-3(cis-hexahydro-2-isoindolinylcarbonyl)propionate (KAD-1229) that acts on the sulfonylurea receptor: comparison of effects between KAD-1229 and gliclazide. J Pharmacol Exp Ther. 1994;269:489-95.

8. Mogami H, Shibata $H$, Nobusawa R, et al. Inhibition of ATP-sensitive $\mathrm{K}+$ channel by a non-sulfonylurea compound KAD-1229 in a pancreatic beta-cell line, MIN 6 cell. Eur J Pharmacol. 1994;269:293-8.

9. Bakkali-Nadi A, Malaisse-Lagae F, Malaisse WJ. Ionophoretic activity of meglitinide analogues. Diabetes Res. 1994;27:61-71. 
10. Director, Evaluation and Licensing Division, Pharmaceutical and Food Safety Bureau, Ministry of Health, Labour and Welfare. Guideline for Clinical Evaluation of Oral Hypoglycemic Agents. PFSB/ELD Notification No. 0709-1; 2010.

11. Kaku K, Tanaka S, Origasa H, Kikuchi M, Akanuma Y. Effect of mitiglinide on glycemic control over 52 weeks in Japanese type 2 diabetic patients insufficiently controlled with pioglitazone monotherapy. Endocr J. 2009;56:739-46.

12. Ono Y, Kameda H, Cho KY. Mitiglinide/voglibose fixed-dose combination improves postprandial glycemic excursions in Japanese patients with type 2 diabetes mellitus. Expert Opin Pharmacother. 2013;14:361-70.

13. Tatsumi F, Hashiramoto M, Hirukawa H, Kimura T, Shimoda M, Tawaramoto K, Kanda-Kimura Y, Anno T, Kawasaki F, Mune T, Matsuki M, Kaku K. Concomitant use of miglitol and mitiglinide as initial combination therapy in type 2 diabetes mellitus. Diabetes Res Clin Pract. 2013;101:35-44.

14. Japan Diabetes Society. Treatment guide for diabetes 2012-2013. Tokyo: Bunkodo; 2012. p. 9-12.

15. Sakura H, Tanaka Y, Iwamoto Y. Seasonal fluctuations of glycated hemoglobin levels in Japanese diabetic patients. Diabetes Res Clin Pract. 2010;88:65-70.

16. Gikas A, Sotiropoulos A, Pastromas V, Papazafiropoulou A, Apostolou O, Pappas S. Seasonal variation in fasting glucose and HbA1c in patients with type 2 diabetes. Primary Care Diabetes. 2009;3:111-4.

17. Tseng CL, Brimacombe M, Minge X, et al. Seasonal patterns in monthly hemoglobin A1c values. Am J Epidemiol. 2005;161:565-74. 